\title{
COMUNIPÓLOGOS: LOS SAS'TRES DEL EMPERADOR, SUS HILOS DE ORO Y LAS LENTES DEL PÚBLICO
}

\author{
JosÉ LUIS DADER \\ Profesor Titular de Comunicación Política. Universidad Complutense de Madrid
}

Resumen

Este artículo describe la complejidad de las actuales estrategias de comunicación gubernamental y las actividades de los 'inductores de noticias'("spin doctors") encargados de los contactos del gobierno con los medios. Estos nuevos expertos han adquirido una posición estratégica en las modernas democracias. En países como Estados Unidos y Gran Bretaña, el Director de Comunicaciones de la Presidencia y sus equipos han adquirido un protagonismo decisivo en los procesos de toma de decisiones, superando la tradicional función de portavoces a la que antes se limitaban. El rol estratégico de la comunicación gubernamental exige una intensa combinación de conocimiento teórico y experiencia práctica en la que se fusionan la pericia periodística, la teoría de la comunicación de masas y el manejo de la ciencia política. El tipo de situaciones en las que se requiere la mayor destreza de estas oficinas de comunicación gubernamental son las situaciones de crisis política o de catástrofe social. El autor plantea una comprensión global de la función informativa de los gobiernos democráticos y de las consecuencias ambivalentes para la democracia del conflictivo escenario de la construcción de la imagen gubernamental, en medio de la competencia abierta entre ciudadanos, prensa y gobierno.

Palabras clave

Comunicación gubernamental, 'spin doctors', imagen pública y comunicación de crisis.

\section{Abstract}

This essay describes the complexity of the governmental communications strategies and the activities of the officials and 'spin doctors' in charge of government media relations. The performance of these new media experts has acquired a strategic position in modern democracies. In some countries like the United States and United Kingdom, the Director of Communications of the Presidency and his/her teams have been involved in a protagonist way in the decision-making process, and not only in the performance of spokesperson position that traditionally corresponds to them. The strategic role of governmental communication demands a prodigious combination of knowledge and expertise that blend journalism experience, mass communication theory and political science fields. The most difficult situations demanding the most for the governments and especially for the communication offices, happen in social and political crisis. The author suggests a global understanding of the information function of democratic governments in providing public explanations of their policies, and the ambivalent consequences for democracy of this struggling scenario of image construction and government-media-citizens competition.

Key Words

Governmental communication, 'spin doctors', public image and communication in crisis. 


\section{INTRODUCCIÓN}

Tal vez los primeros asesores de la comunicación presidencial y de gobierno fueron del estilo del incomprendido bardo de la aldea gala de Astérix y Obélix, empeñado en cantar las gestas victoriosas de la tribu, pero condenado una y otra vez a la indiferencia y la mordaza mientras todo el pueblo celebra a su aire los triunfos. El bardo Asurancetúrix, como se le llama en la traducción española de las historietas de Goscigny y Uderzo, bien podría ser reivindicado como el patrón simbólico de todos los confeccionadores de la imagen pública presidencial, pues al igual que ellos vive en un plano secundario, al lado del Gran Jefe, afanándose por tejer, como una segunda atmósfera, la fascinación popular por los héroes ejecutivos. El nombre del imaginado antecesor de la comunicología presidencial resulta todavía más duro y revelador en la versión inglesa y la original francesa del cómic, ya que no es otro que el de CACOFONIX; es decir, la negación intrínseca de la armonía y el buen sonido. Problema que sin duda acompaña a nuestros contemporáneos del puesto, porque irónicamente nadie sigue padeciendo peor imagen que los especialistas en la mejoría del aura pública e institucional de los demás².

$Y$ sin embargo, resulta revelador que, a pesar de tanta indiferencia o desprecio popular por su tarea, el astuto y orondo Jefe de la tribu gala jamás aparta al pobre Cacofónix de su lado ni osa rebatirle. Permite, eso sí, que el populacho se mofe de él y hasta le ate a un árbol lejos de la mesa comunitaria en la noche de los festejos, pero desde luego no se le ocurrirá retirarle la financiación pública que le permite vivir holgadamente -incluso con la vestimenta más sofisticada-, sin que se le conozca la práctica de cualquier otro oficio. Es más, si profundizamos en la exploración semiótica del cuento, podríamos preguntarnos, cómo en una época de tanta truculencia política, el Jefe Abraracurcix no ha sufrido el menor conato de golpe de Estado ni su popularidad ha sufrido caídas de veinte puntos poniendo en crisis sus agresivas políticas anti-romanos ${ }^{3}$.

Los gobiernos y presidentes de Estado, democracias incluidas, hace mucho que comprendieron, como el Jefe Abracurcix, que la política material de las intervenciones sociales y económicas puede pasar desapercibida y hasta arruinar su eficacia, si al mismo tiempo no se confecciona todo un envoltorio simbólico que dote a aquellas medidas de prestancia, justificación moral y reconocimiento popular. Y para la confección de esa segunda política simbólica, se ven abocados, ya en los tiempos actuales, a rodearse de un raro tipo de sastres de los mensajes gubernamentales,

\footnotetext{
2 Como escribe Roberto Izurieta (2002:222-223) refiriéndose a los portavoces de gobierno, "de los trabajos más difíciles de realizar y con mayor inestabilidad es el de la vocería. Todo el mundo tiende a criticar a un vocero. Es normal si consideramos que un vocero no puede ser un experto en todos los temas". Y respecto a su complementario y casi inseparable "experto en relaciones públicas", el mismo autor añade (lbíd. 228): "la mayoría de la gente no sabe qué hacer con los relacionadores públicos; es más, los tienen porque la competencia los tiene o hay que tenerlos". Priemer (1989: 229, citado por el anterior) apostilla: "Los relacionadores públicos han sido mantenidos por mucho tiempo a un lado de la toma de decisiones pues han sido considerados con poca capacidad y poco que aportar para la creación de un producto determinado".

3 Y es que, siguiendo de nuevo a Izurieta (2002:223), el suyo "es un trabajo necesario. El vocero es en realidad el primer fusible de un gobierno".
} 
que cabría calificar de comunicopólogos por su compleja habilidad de combinar los conocimientos sobre la comunicación social y la persuasión mediática con la propia reflexión sobre las alternativas de acción política.

La comunicación gubernamental y de Estado ha experimentado una profunda densificación en las últimas décadas para responder al reto de unas sociedades comunicativamente mucho más complejas, en las que el capital simbólico añadido, o imagen, cada vez exige más espacio al originario territorio de las materias primas políticas. Los consejos que Maquiavelo diera en su día al Príncipe ya no bastan para orientar sus relaciones públicas y el despliegue que ahora se requiere para ponerlas en práctica ya no puede limitarse al cuidado de las declaraciones aisladas que el presidente o miembro de un gobierno haya de ofrecer. En el caso de las democracias, ni siquiera el aluvión de actividades de campaña desplegadas en el período electoral serán ya suficientes para sostener al Ejecutivo entrante. Pues como señalan casi todos los especialistas, al día siguiente de conquistar el Poder ha de comenzar ya la preparación del próximo refrendo electoral, quedando así instaurada la campaña permanente (cfr. por ej. Blumenthal, 1980; Canel, 1999:75 y ss.; Noguera, 2002).

El cúmulo de aspectos que, en consecuencia, ha de considerar la comunicación presidencial y gubernamental más actual, exige una comprensión global a partir de la estructuración previa de sus componentes. Y aun siendo conscientes de la imposible explicación pormenorizada en el breve lapso de un artículo, intentaré al menos ofrecer una aproximación a los que, en mi opinión, constituyen los puntos neurálgicos sobre los que articular un sistema de comunicación presidencial y gubernamental democráticamente legitimado y técnicamente avanzado.

\section{LOS NUEVOS RESPONSABLES DE LA COMUNICACIÓN PRESIDENCIO-GUBERNAMENTAL}

La presidencia de Ronald Reagan en Estados Unidos marca sin duda un antes y un después en la configuración y perfil de los diseñadores de la representación comunicativa del presidente de una democracia. Obviamente, muchos otros presidentes y en muchos otros países habían contado antes con jefes de prensa, portavoces oficiales, asesores de marketing político y otros diversos ayudantes de la confección de la imagen pública del gobernante ${ }^{4}$. Pero nunca antes esas diversas tareas se habían ejercido de manera tan coordinada, tan intensa y tan seductoramente desplegadas como envoltorio -y hasta cortina de humo-, por encima de la acción material de gobierno. Con

\footnotetext{
${ }^{4}$ Ya Roosvelt en los años 30 utilizó algunos métodos de contacto directo con el público para generar una buena imagen de su política "Charlas junto a la chimenea" transmitidas a través de la radio- (cfr. Ewen, 1996:240) y Nixon, cuando era candidato a vicepresidente con Eisenhower, en 1952, consiguió desmontar un escándalo de supuesta aceptación de sobornos, a través de una comparecencia en un programa en televisión -su conocido discurso del perrito "Checkers"-, para presentar como inverosímil la acusación. Para ello desvió la atención hacia la emotividad popular con la revelación de que a su pequeña hija le habían regalado un perrito durante la campaña, que por supuesto no pensaba devolver para no partirle el corazón a su niña y no teniendo por supuesto ni él ni su familia nada de qué avergonzarse (cfr. Izurieta, 2002: 206; Thompson, ed. 2001, 250-51, entre otros). El propio Nixon, ya presidente, crearía en 1969 de manera permanente la Oficina de Comunicación de la Casa Blanca para coordinar los mensajes de su gobierno ante los medios (Alger, 1996:2421.
} 
Ronald Reagan como actor supremo, el gabinete de planificación político-comunicacional de su presidencia inaugura una forma de neopopulismo radical que el científico de la política Samuel Kernell (1986) ha bautizado como "Going to Public".

Ese "apelar al público" mediante mensajes emotivos, manejo calculado del impacto mediático y refrendo inmediato en encuestas de popularidad -que a su vez retroalimentan la espiral populista-, parecería en principio la respuesta natural, a lo sumo más perfeccionada, al principio democrático de gobernar de cara al pueblo y no de espaldas a él. Pero lo que marca el rasgo de la novedad, y hasta del dudoso encaje del mecanismo en el proceso democrático tradicional, es la utilización estratégica de esos resortes para desactivar el diálogo y la negociación pluralista de diversos sectores organizados de opinión. Cada vez que la oposición política o movimientos sociales realizaban una crítica o exigían un debate, conforme a los cauces tradicionales de la negociación parlamentaria o institucional, el presidente en rápidas apelaciones emotivas, reforzadas por su simpatía de persona sencilla, se arropaba en la bandera de su sintonía popular, como argumento más inapelable que cualquier tecnicismo o análisis esgrimido por sus adversarios. Oponerse a las políticas del Presidente sería enfrentarse al sentimiento popular que lo respaldaba, y en una sociedad tan sensible a la aritmética democrática, ni medios de comunicación, ni opositores políticos están muy dispuestos a combatir un clima de opinión popular bien visible y firme, por más que ese clima pudiera ser el resultado de una sugestión fabricada.

El discurso y la imagen de Reagan, según la han diseccionado diversos especialistas (Perloff, 1998: 105 y ss.; Paletz, 1999:247-249; Carville y Begala, 2002) consistió en un calculado ejercicio de construcción de escenarios grandiosos en los que mostrar al presidente -aunque apenas hablara-, para reforzar su figura ceremonial y la asociación visual de símbolos favorables; se apoyaba en la preparación de textos de retórica directa y sentimental que Reagan leía con toda la fuerza de autoconvicción y verosimilitud de su entrenada capacidad dramática; y todo ello reforzado por el propio Reagan con su predisposición al optimismo y sus reacciones espontáneas de gracia y encanto personal, que le conquistaban el favor hasta de los periodistas más escépticos, incluso cuando su torpeza intelectual y sus meteduras de pata pudieran también resultar memorables ${ }^{5}$.

En la preparación de toda esta tramoya participó un selectivo grupo de comunicopólogos, a los que habría que denominar así (o con otra palabra mejor aún por inventar ${ }^{6}$ ) para subrayar la in-

\footnotetext{
5 De su sentido del humor contagioso y espontáneo da idea la siguiente frase que le dijo a su esposa tras resultar herido por los disparos de John Hinckley en el atentado sufrido durante su primer mandato: "Cariño, olvidé esquivarlos" (Carville y Begala, 2002:117).

- Izurieta (2002), por ejemplo, utiliza el término de "relacionadores públicos" para traducir la expresión inglesa "public relations" y habla expresamente de los "relacionadores públicos del gobierno", (lbíd..: 220) para referirse a los especialistas del sector que se dedican a la aplicación de esta función al servicio de un gobierno. Pero teniendo en cuenta que dentro del equipo gubernamental destinado a estas tareas puede diferenciarse luego entre la portavocía de gobierno (ejercida por políticos o por profesionales de la comunicación), la jefatura de prensa, la oficina de estrategia de comunicación, etc., y teniendo en cuenta además que la combinación y coordinación de estos cometidos requiere una fusión de perspectivas políticas y comunicológicas, prefiero utilizar el "palabro" arriba presentado para subrayar esa necesidad de síntesis entre enfoques diversos en una especialización profesional que todavía no está suficientemente sedimentada.
} 
tegración de conocimientos comunicológicos y politológicos que por primera vez fueron estratégicamente compactados. Entre los miembros de ese equipo me permito destacar a Richard Wirthlin y David Gergen, tanto por su aportación decisiva como por la nueva función que personas de su perfil pasaron a desempeñar en el centro neurálgico del poder Ejecutivo.

En el caso de Wirthlin, en origen un profesor de economía, virtuoso de la estadística, que había creado su propia empresa de análisis informático de datos, se trataba del diseñador del plan de encuestas electorales cuyos resultados diarios sincronizados con las presentaciones del candidato de los temas y posturas así detectados, llevaron la campaña de Reagan en 1980 a una inesperada y al mismo tiempo aplastante victoria. Pero lo más extraordinario fue que tras ese triunfo, Wirthlin pasó a formar parte de los asesores directos del Presidente, compartiendo poder e iniciativa en la planificación presidencial con el mismísimo jefe de gabinete James Baker y los ministros de gobierno de mayor peso político. Quien en definitiva era un asesor de campañas electorales, en su vertiente mercadotécnica, pasaba a participar tan activamente en la sala de máquinas del Poder Ejecutivo como los políticos integrantes del gabinete presidencial (Perry, ed. 1986; Wirthlin, 1995). Y lo mismo cabe decir de Gergen, quien ya había colaborado con Nixon, pero que ahora, plenamente sincronizado en esta fusión de comunicólogos, politólogos y políticos se convirtió en el maestro de la planificación de las relaciones con los medios, distribuyendo las comparecencias, las entrevistas en exclusiva y el reparto de papeles declarativos entre el Presidente -pocas y medidas veces- y el superministro Baker -hasta 35 horas semanales conversando con periodistas(Paletz, 1999:248).

Como resultado de toda esa acción conjunta de trastienda, otro de los responsables de la parte comunicacional durante el segundo mandato presidencial, Donald Regan -de similar apellido al del Presidente-, llegó tiempo después a escribir que "cada instante de cada una de las apariciones públicas estuvo programada, cada palabra estaba escrita en un guión, y hasta todo punto en el que Ronald Reagan debiera aparecer de pie estuvo indicado con una tiza marcando la posición exacta de sus zapatos" (Donald Reagan, 1988:277)7.

La nueva figura del experto en estrategias comunicativas que tras su probada pericia en campaña electoral pasa a ejercer un puesto esencial de influencia política al lado del Presidente, ha sido a partir de entonces cada vez más habitual en diversas democracias. Si bien los problemas y variedad de opciones sobre el peso de su influencia requieren también alguna atención. Su propio encaje institucional continúa presentando una difusa demarcación. Así por ejemplo, cuando a Paul Begala, máximo responsable de la comunicación presidencial de Bill Clinton, se le pedía en una revista académica una denominación de su puesto, se autopresentaba simplemente como "Consejero del Presidente". Y definía su tarea del siguiente modo:

Como ha escrito Perloff (1998:114), "uno se siente inquieto cuando considera que Reagan no escribió ni uno solo de sus discursos, que para plantear sus mensajes dependía por completo del equipo de redactores que se los escribía, y sin embargo resultaba extraordinario a la hora de leer los textos que otros escribían. 
"Ayudo a desarrollar las medidas políticas, aunque francamente mi pericia tiene que ver más con la parte comunicativa (...) Una vez que el presidente ha decidido que quiere hacer equis, (intervengo) en cómo hay que ejecutar y explicar eso". Si bien añadía: "He participado en todos los debates del presupuesto (...) y claramente tengo un sentido político de lo que probablemente resulte más popular y lo que no". A todo lo cual añadía la certificación de que: "Yo soy un miembro del bloque completo de gente que engarza todas estas cosas. Trabajo con el equipo de prensa, con el equipo de comunicaciones, con otros dos o tres asesores principales (y en momentos concretos con los responsables específicos de algunas otras áreas)" (Kalb, 1998:6-7).

Como puede deducirse de esta declaración, el cambio sustancial de las funciones de los responsables de la comunicación presidencial consiste en: 1) Se trata de una figura de rango muy superior a la del portavoz oficial o jefe de prensa, cuya actividad sigue presente, pero supeditada a esta nueva dirección, 2) Tanto si se trata de un único experto o de varios, son designados directamente por el Presidente, al margen de y en cierto modo por encima de la estructura política de los ministros, 3) Aunque su competencia es en origen de tipo técnico y circunscrita al ámbito comunicativo, ese ámbito ya no puede desligarse de la discusión y elección de propuestas políticas concretas, pasando en la práctica a convertirse en un ministro o miembro más del gabinete político, 4) Pero al depender directamente de la confianza presidencial, queda a menudo por encima del resto del Consejo de Ministros, lo que además de conferirle una influencia extraordinaria de borrosa identificación genera consecuencias ambivalentes: En sentido positivo permite coordinar las perspectivas parciales de cada ministerio, pero en sentido negativo puede generar resentimiento y obstaculización por parte de los ministros políticos que suelen recelar de la intromisión de una figura no emanada de la burocracia interna del partido o partidos gobernantes, y 4) Aun con las dificultades de ese difícil encaje, su función está destinada a integrar una amplia red de recolección, elaboración y diseminación de información. La necesidad de su papel se justifica por su celeridad de acción, flexibilidad de intervención y adaptación a los cambiantes entornos mediáticos. Sólo él puede soslayar los lentos procesos de las negociaciones internas y los pactos entre áreas rivales internas, que tan a menudo esclerotizan la discusión política en el seno del propio gobierno. De ahí entonces el nombre de "consejeros" y la negativa a una definición institucional precisa, en aras de una mayor eficacia.

La complejidad de su función y la calculada ambigüedad de su definición político-comunicativa produce en la práctica que cada país, e incluso que cada equipo presidencial establezca su propio diseño al respecto, influyendo en gran medida la propia personalidad de los elegidos para el cargo, así como la del presidente y su pequeño grupo de "íntimos" que deciden con él el nombramiento de este o estos superministros de la puesta en escena. La dificultad de dar con el equilibrio perfecto entre autonomía, coordinación y combinación de política y técnica representacional explica la variedad de soluciones ensayadas y hasta los cambios bruscos de personas y modelos. En algunas ocasiones, como sucediera en España con el portavoz oficial del primer gobierno de Aznar, Miguel Ángel Rodríguez, el respaldo presidencial a su libertad de actuación, basada en su probada eficiencia marquetínica -había sido el jefe de prensa de las campañas electorales de Aznar y se trataba de un antiguo periodista-, derivó en atribucio- 
nes políticas estrictas que aun aplicadas a las regulaciones sobre medios de comunicación, generó tal controversia y desgaste político general que diluyó por completo su sentido original de coordinación y orientación de la imagen y el discurso presidencial. En una clásica reacción pendular, la dirección de la comunicación gubernamental y presidencial de los gobiernos de Aznar ha sido asignada después a ministros políticos que por su experiencia profesional en empresas de comunicación (caso de Pío Cabanillas) o por sus dotes naturales para el intercambio dialéctico con los medios (el siguiente portavoz y vicepresidente político Mariano Rajoy), supuestamente pudieran asegurar una buena imagen general del Presidente y su gobierno sin estar a merced de incontrolados rasputines de trastienda, ajenos a la militancia partidaria y la constricción de unas competencias administrativas específicas.

En esta otra opción, en la que algunos expertos de comunicación estrictos siguen dentro del equipo pero en calidad de subordinados para emitir dictámenes o consejos previamente solicitados, se mejora en cohesión interna y eliminación de recelos competenciales, pero como puso de manifiesto en España la terrible crisis del hundimiento del petrolero "Prestige", en noviembre de 2002, se suele empeorar de tal manera en cuanto a celeridad de respuesta y sentido comunicacional de la política que prácticamente desaparece el sentido de los gabinetes de comunicación gubernamental y se retrocede a fórmulas de veinte años atrás; como si la experiencia ya aludida de Estados Unidos y otras democracias mediáticamente muy activas no hubieran demostrado que la conexión entre política y comunicación en nuestras sociedades postmodernas obliga a poner en práctica otro tipo de estructura y de actuación seguramente más inestable y arriesgada pero de eficacia mucho más contundente cuando se acierta con la tecla justa.

Precisamente en el seno de otra de las democracias que más ha evolucionado en materia de comunicación gubernamental, la británica, puede analizarse el contradictorio balance que el sometimiento de la acción política a su representación comunicativa puede acarrear. Cuando por decirlo con frase irónica, se puede fracasar por exceso de éxito.

En el caso británico, el cambio experimentado en la utilización estratégica de la comunicación como instrumento político, por un líder y un gobierno, es sin duda el más radical de cuantos se comentan hoy día entre los especialistas del área. Me refiero a la transformación mediática y representacional del partido laborista, bajo la dirección de su líder Tony Blair y su macroconsejero comunicacional Alastair Campbell. Como primer dato sintomático cabe recordar que cuando el anterior líder laborista Neil Kinnock se presentó por última vez a unas elecciones generales en 1992, la poderosa cadena de prensa populista de Rupert Murdoch daba el tiro de gracia a sus mínimas aspiraciones con el siguiente titular en el diario populista The Sun, el mismo día de los comicios: "Si este hombre gana mañana las elecciones, que el último ciudadano en abandonar el Reino Unido apague la luz". Sin embargo, cuando pocos años más tarde Tony Blair obtuvo el liderazgo del partido laborista, una de sus primeras decisiones fue la de visitar a Murdoch para solicitar su apoyo en las siguientes elecciones. Y, en efecto, esa misma cadena de prensa apostaba directamente por el nuevo laborismo en la campaña de 
1997, arrancando el primer día de la campaña oficial con el titular de "The Sun Backs Blair" (Elliot, 2001; Norris et al, 1999:25 y ss). Por ese respaldo o además de él ${ }^{8}$, dicho candidato se convertía en uno de los jefes de gobierno con trayectoria más carismática y refrendo electoral revalidado de los últimos tiempos. Lo que había sucedido entre tanto no sólo era la reconfección por un equipo de sociólogos e ideólogos de un laborismo más a la moda bautizado como "Tercera Vía", sino la redefinición de imagen y de adaptación estratégica de ese laborismo a las exigencias del discurso mediático. Y en esa transformación, un antiguo director de periódicos populistas (a la edad de 29 años) y hasta redactor de textos pornográficos para revistas masculinas, llamado Alastair Campbell, había jugado uno de los principales papeles ${ }^{9}$ (BBC:2002; Maguire, 1999).

Tras la victoria en 1997, el citado Campbell pasó a convertirse, bajo la denominación de Jefe de la Secretaría de Prensa del Primer Ministro, en un plenipotenciario muñidor y administrador de la imagen presidencial (aunque en Gran Bretaña haya que hablar de Primer Ministro), al que muchos han calificado de "el auténtico primer ministro" y "la segunda persona más poderosa de Gran Bretaña" (BBC:2002). Su tarea, intensamente guiada por la perspectiva que en inglés se denomina "the politics of spin" (y "spin doctoring") -o reconversión de toda acción política a parámetros de impacto mediático y mercadotecnia ${ }^{10}$-, no sólo supuso, de cara al exterior, un cambio de extraordinaria favorabilidad del tratamiento de Blair en todos los medios británicos, sino también, hacia el interior, un rígido control y una exhaustiva coordinación de las secretarias de prensa de todos los ministerios y departamentos gubernamentales.

\footnotetext{
8 De hecho, en un cambio de tendencia sin precedentes, no fue sólo el Sun quien respaldó a Blair en esa campaña: seis de los diez diarios de mayor difusión y cinco de los nueve dominicales lo hicieron, con unas cifras de apoyo periodístico declarado que doblaban las mejores nunca antes obtenidas por los laboristas (cfr. Norris et al, 1999:25 y Seymour-Ure, 1997).

- Sin restar importancia al papel técnico de Campbell, está reconocido, sin embargo, que el principal estratega del cambio de enfoque político y "genio de la imagen" del nuevo laborismo fue el parlamentario Peter Mandelson, quien era diputado desde 1992 y desempeñó el puesto de Director de Comunicaciones del partido y más tarde sería ministro sin cartera en el primer gobierno de Tony Blair. Asimismo, el estratega político Philip Gould, con la responsabilidad del área de comunicación en el "Gabinete en la sombra", en esos años de oposición, también es citado como otro de los artífices de esa transformación político-comunicativa (cfr. Thompson, ed. 2001:239 y Norris et al., 1999:1 y 58).

${ }^{10}$ Se ha escrito, en este sentido, que en la llegada al poder del Nuevo Laborismo, entre el político Peter Mandelson y Alastair Campbell, condujeron el partido como si fuera un periódico, convirtiéndose Campbell en el Director del "Daily Blair" (Rawnsley, 2002). Las expresiones "spin doctoring" y "spin doctors", por otra parte se han hecho muy populares para referirse al conjunto de asesores de imagen y de enfoque mediático que asisten a los políticos en sus campañas electorales y en el ejercicio de sus cargos políticos. Pero como explica Izurieta (2002:21 1), el sentido más específico y originario de la expresión se refiere a la función de buscarle "el giro" o el matiz periodístico más favorable a los intereses del político en las declaraciones o actuaciones de éste ante los medios. El ejemplo de experto más reconocido en esta faceta, como recuerda el mismo autor, es David Gergen que trabajando para presidentes tan distintos como Nixon, Reagan y Clinton acostumbraba llamar por teléfono a los medios para reforzar el "spin" dado en la presentación de la noticia.
} 
El paradigmático poder de sincronización de Campbell cristalizaba en la reunión diaria que a las nueve de la mañana mantenía con todos los responsables de cada ministerio para marcar la agenda comunicativa global y evitar la menor discrepancia. Su poder omnímodo y versátil provocaba que una llamada suya a cualquier político o parlamentario del gobierno fuera interpretada por todos ellos como emanación directa de la voluntad del propio Primer Ministro, siendo notoria la estrecha y antigua amistad entre ambos, que a menudo se ha venido reforzando con sus apariciones conjuntas en celebraciones o espacios de ocio. Las intervenciones de Campbell servían para establecer con rapidez el curso de los acontecimientos que mostrar ante las demandas o inquisitorias de los medios, protegiendo la figura de su jefe de gobierno y evitando las situaciones de contradicción interministerial o parálisis. Pero también hay que anotar su indisimulada proclividad al estrellato en actos oficiales, comparecencias públicas y hasta duros artículos de su puño y letra contra la oposición, que le han ido granjeando enemistades en sus propias filas y críticas por extralimitación de funciones, desde la oposición (cfr. por ej. Maguire, 1999; Rawnsley, 2002).

Pero toda esa visibilidad del gran "cerebro comunicacional" y la progresiva sensación de que la política de Blair contenga más artificio mediático que sustancia real, comenzó a generar desconfianza entre los medios y un movimiento de rechazo entre los ciudadanos, alimentado por la acumulación paulatina de conflictos en los que la figura de Campbell iba personificando todo lo que de oscuro y negativo pueda tener la política. La propia perspicacia de Campbell le llevó primero a huir hacia arriba, delegando su coordinación del día a día para pasar a un puesto de planificación a largo plazo en un nuevo cargo de "Director de Comunicaciones", y haciendo una declaración explícita de abandono del excesivo componente de "spin doctoring" que la comunicación gubernamental del gabinete había utilizado en los últimos tiempos (BBC, 2002; Epx, 2002). Sin embargo, como ya es notoriamente sabido, sus implicaciones en el "cocinado" ante la opinión pública de los documentos secretos que justificaron la participación de Gran Bretaña en la guerra contra Irak, en la primavera de 2003, han terminado por provocar, al final de este mismo verano, la renuncia definitiva de Campbell de cualquiera de sus funciones o cargos, más o menos difusos, en el gabinete de Blair.

La principal lección que cabe extraer de la sobredosis de éxito experimentada por Campbell es que, siendo probablemente indispensable la inclusión de una enérgica estrategia comunicacional en la acción gubernamental contemporánea, el experto o cerebros de esa política no deben sobrepasar en protagonismo a sus asesorados, ni tampoco priorizar de tal modo la política de los gestos frente a los contenidos de las medidas, que toda la actividad política de un gobierno y de su presidente termine por mostrar la apariencia de una cáscara vacía sospechosamente revestida además de falsificación y surpechería ${ }^{11}$.

\footnotetext{
$"$ Como ha escrito Andrew Rawnsley (2002) "Son precisamente esas técnicas adoptadas para combatir a la prensa las que ahora son utilizadas para describirle a él (Tony Blair) como el turbio líder de un régimen de mendacidad. Y todo esto dicho antes de que la crisis por la supuesta manipulación de los informes sobre Irak y la controversia con la BBC, con el suicidio incluido de uno de los principales expertos en la materia, haya estallado y supuesto un escándalo monumental a lo largo de 2003
} 


\section{LA ESTRUCTURA DE LOS SERVICIOS DE INFORMACIÓN Y COMUNICACIÓN DEL ESTADO}

Tras la reflexión sobre el grado de protagonismo de los sastres mediáticos del gobierno, conviene de inmediato ocuparse de la dimensión y estructura general de la red comunicativa empleada. De manera intencionada he venido utilizando hasta aquí el barroco término de "comunicación presidencio-gubernamental", para indicar que la comunicación política organizada desde el Poder Ejecutivo contiene dos facetas que a veces se limitan a la primera, en otras se plantean de manera disociada y otras reciben un tratamiento global y coordinado.

La primera tentación de todo líder que alcanza el Poder, sobre todo si se trata de un sistema presidencialista, estriba en cuidar la imagen de su propia figura presidencial y dejar a la inspiración de cada cual la actividad de los ministerios y restantes áreas de la Administración. Puede fraguarse así un gran culto a la personalidad del Presidente, marcando una enorme distancia entre sus comparecencias y contacto popular, y la difusa y diversificada actuación del resto del gobierno y la Administración ${ }^{12}$. Ello puede ayudar al máximo dirigente a reforzar su autoridad, pero como también se pone amargamente de manifiesto en las crisis de negligencia o fiasco administrativo, la falta de sincronía y de integración de toda la maquinaria del Estado en una estrategia comunicacional coherente puede resultar a la postre dañina para la popularidad del propio Presidente.

Un primer esfuerzo por integrar las diversas facetas diferenciando al mismo tiempo cada cometido es el que refleja la evolución de los servicios presidenciales y de gobierno de la Casa Blanca en materia comunicativa, distinguiendo entre la Oficina de Prensa -encargada del trabajo cotidiano de la agenda informativa del Presidente-, y la Oficina de Comunicación -de dimensión más estratégica y a largo plazo-, involucrada en la planificación de campañas pro-activas sobre diversos asuntos, la sincronía comunicativa entre los diversos ministerios, etc. (lzurieta, 2002:210-11). Pero luego a su vez, habría que tener en cuenta la actividad informativa desplegada de manera autónoma por cada ministerio u oficina de la Administración. Respecto a este tercer escalón, mucho más vasto y complejo de la respuesta informativo-comunicativa del Estado y la Administración, los países más organizados han ido generando una compleja red en la que el reto principal consiste en combinar la máxima respuesta informativa de cada ministerio y oficina con la mayor coordinación entre la imagen que refleja el presidente y su gabinete y la que emana desde el resto de las dependencias del Poder Ejecutivo.

Pocos países como, de nuevo, Gran Bretaña le han dado tanta importancia a la estructuración de un servicios de información musculosos y bien coordinados, que eviten una sensación de anarquía interna. A la ya mencionada estrategia de armonizar a diario la agenda de declaraciones políticas de las secretaría de prensa de cada ministerio, impidiendo el clásico individualismo de cada departamento, se añade la existencia de dos organismos de proporciones gigantescas: el GICS, o "Government Information and Communication Service", con una plantilla de varios centenares de

${ }^{12}$ El caso de Hugo Chavez puede resultar en esto paradigmático. 
funcionarios, diseminados a lo largo de todos los ministerios y organismos públicos ${ }^{13}$, y el $\mathrm{COI}$, "Central Office of Information" constituido éste como un centro especializado en tareas de publicidad, marketing y relaciones públicas, con una plantilla de casi 400 miembros y su propio edificio de trabajo en el centro de Londres ${ }^{14}$. Estas dos grandes redes constituyen el esqueleto aglutinante de la comunicación del sector público y se encargan de asistir a cada ministerio con el asesoramiento técnico, recursos de producción audiovisual y ayuda en el desarrollo de campañas informativas de todo tipo. De esta manera, en lugar de despilfarrar en la superposición de estructuras similares montadas y desmontadas al criterio de cada nuevo responsable ministerial, estos servicios centralizados de información, publicidad y relaciones públicas rentabilizan recursos y permiten un grado de coordinación de "imagen corporativa" y de sentido político unitario que redundará sin duda en una visión pública más compacta de la Administración, el gobierno, su presidente y el propio Estado ${ }^{15}$.

\footnotetext{
${ }^{13}$ El GICS es una red capilar de funcionarios especializados en tareas de elaboración y difusión de información, relación con los medios, lanzamiento de campañas informativas y mantenimiento de información de la Administración hacia el público, cuya dirección jerárquica depende directamente de la Unidad Estratégica de Comunicación del Primer Ministro. El Director del GICS, o "Head of Profession" es nombrado por el Cabinet Secretary del Primer Ministro, con el conocimiento previo y aprobación de éste. Su peculiaridad principal reside en la doble vinculación de sus miembros: Por una parte todos ellos son contratados y supervisados desde su dirección central, estando sujetos al cumplimiento de unos estándares de trabajo sintetizados en el Manual de Prácticas del GICS. Pero una vez destinados a un ministerio o departamento de la Administración, quedan adscritos orgánicamente a éste y se encargan de materializar las iniciativas y necesidades del mismo conforme a los planteamientos técnicos generales que emanan de la dirección del GICS. Con este procedimiento se evita que cada ministerio lleve su propia política de contratación de expertos en organización de unos servicios informativos, pero al mismo tiempo se logra que los mantenedores de los servicios de información en cada organismo lo hagan desde el conocimiento inmediato y respondiendo a las necesidades específicas de cada uno. Como objetivos estratégicos de su labor el GICS establece: 1) Explicar las medidas prácticas y actuaciones de los ministros y sus departamentos, así como de todas las oficinas u organismos autónomos de la Administración, 2) Facilitar a los ciudadanos y grupos sociales una idea clara de los derechos, beneficios y obligaciones que la Administración les plantea y ofrece, 3) Convencer a los ciudadanos de que actúen de acuerdo con las medidas públicas acordadas en circunstancias específicas y 4) Asegurar y demostrar el uso correcto del dinero de los contribuyentes (cfr. www.gics.gov.uk/handbook/context/ y www.cabinet-office.gov.uk/organisation/ ).

${ }^{14} \mathrm{El} \mathrm{COI}$ es un organismo de la Administración británica dotado de presupuesto autónomo (unos 270 millones de libras para el período 2001-2002) y oficinas centralizadas en la calle Hercules Road de Londres en las que trabajan entre 350 y 400 técnicos especializados en marketing, publicidad e imagen corporativa. Más de la mitad de su plantilla tiene experiencia previa en el sector privado y por el volumen de su actividad puede considerarse uno de los grupos más potentes de inversión publicitaria en el Reino Unido. Sus tareas abarcan desde estrategias de marketing y campañas publicitarias a preparación y mantenimiento de páginas web, organización y gestión de congresos, etc. Su función básica es definida como intervención de puente entre el gobierno central y los proveedores privados en materia de publicidad y relaciones públicas -el organismo declara su propósito de no competir con los servicios que el sector privado sea capaz de facilitar en la ejecución de las actividades-. Pero previamente a esa contratación final de servicios, este organismo está concebido como una entidad planificadora y organizadora al servicio del gobierno central que, a su vez, trabaja como experta que se asocia a cada ministerio u oficina de la Administración -su "cliente"-, para proporcionarle "soluciones comunicativas efectivas" que generen "valor añadido a cada proyecto" para la oficina o sección de la Administración que solicite su asesoría. El Director del COI también ostenta el cargo de Director de Asesoría en Marketing Comunicacional del Gobierno y despacha directamente con el Director de Estrategia y Comunicaciones del Primer Ministro (hasta hace poco, el citado Alastair Campbell) (cfr. www.coi.gov.uk y www.cabinet-office.gov.uk/organisation/).

${ }^{15}$ La profesionalidad y definición precisa de las tareas de estos servicios informativos, abarca incluso el peliagudo asunto de evitar su instrumentalización por el partido gobernante durante las campañas electorales. En algunos países como Sudáfrica, dotados de una estructura basada en el modelo británico, desde abril de 1999, el GICS sudafricano está dotado de un código de prácticas de actuación informativa durante campañas electorales para intentar separar la actividad regular de información sobre la Administración, de la contienda electoral (cfr. www.polity.org.za/html/govdocs/pr/1999/pr0429c.html)
} 
La coordinación centralizada de estos servicios va siendo cada día más asumida, sobre todo por países herederos de la tradición británica. En otros como España es patente su carencia, y de ahí algunos de los fracasos a los que luego me referiré en el capítulo de las crisis. De cara a fomentar, por tanto, la implantación de este tipo de estructuras transversales de la información gubernamental, a su vez coordinada en la cúspide con la comunicación presidencial, aludiré someramente a los puntos de partida que en su implantación algunas administraciones en vías de desarrollo o de renovación comunicativa han considerado en los últimos años.

Es el caso de países tan dispares como Sudáfrica, Nueva Zelanda o buena parte de los exmiembros del bloque comunista europeo, quienes en los años noventa se enfrentaron al reto común de construir una estructura de información global de sus administraciones. Como señala para los citados países europeos el húngaro Bart Édes (2000) la configuración de una eficaz y transparente estructura de comunicación gubernamental se ha convertido, no ya en una posibilidad de actuación propagandística al servicio de los intereses del gobernante, sino en "un derecho fundamental de los ciudadanos de una democracia eficiente, que han de saber qué es lo que sus funcionarios públicos están haciendo". Por consiguiente, esa red de funcionarios de la información gubernamental estarán dedicados a tiempo completo a "facilitar la circulación de información entre los diversos organismos del Estado, de una parte, y los medios de comunicación y el público, de la otra". El problema práctico que todo Estado tendrá que solventar a continuación es, en opinión del mismo experto, que "incluso el gobierno más abierto y bien intencionado puede dudar respecto a qué cantidad y qué tipo de información debe compartir con la prensa y la población (ibid. 2000:456).

Poner en funcionamiento una red coordinada de estas características resulta difícil incluso en los países que muestran una mayor tradición al respecto, pero como añade el referido experto, el problema se acrecienta en los países en transición, provenientes de culturas políticas tradicionales o de reciente incorporación al pluralismo democrático. La cultura del secretismo gubernamental o el hábito de las imposiciones y las amenazas como viejas recetas de "persuasión", la carencia de una formación previa de especialistas multidisciplinares en la información pública (que implica conocimientos y tareas mucho más variadas que la simple elaboración de resúmenes y comunicados de prensa), e incluso, por parte de los periodistas, la insuficiencia de una cultura profesional habituada a la confirmación por varias fuentes, la distinción entre realidades y rumores, etc., son algunos de los obstáculos añadidos que el citado analista señala a la hora de poner en pie un nuevo sistema de comunicación gubernamental y administrativo. Dicho sistema resultaría simultáneamente útil a la legítima voluntad del Ejecutivo de promocionar sus propuestas y al derecho de la ciudadanía a obtener una información suficiente y transparente de la acción de gobierno.

Respecto a los problemas que un sistema avanzado de comunicación gubernamental debiera solventar en cualquier país donde se afronte tal reforma, quizá nada haya más sintomático y extrapolable que las deficiencias detectadas en Sudáfrica ${ }^{16}$, cuando la comisión sobre comunicación

\footnotetext{
${ }^{16}$ Aunque más centrado en los aspectos de la información administrativa accesible a los ciudadanos y la posible mejora a través de Internet de esta comunicación entre los departamentos gubernamentales y el ciudadano, aporta también ideas complementarias de gran interés el extenso informe elaborado por una comisión de expertos para el Estado de Nueva Zelanda (Yeabsley y Bailey, 2001).
} 
gubernamental, creada al efecto, presentó sus conclusiones en 1996, para la puesta en marcha de un sistema general de información y comunicación (GICS) para el nuevo Estado democrático presidido por Nelson Mandela ${ }^{17}$. Los retos a superar eran: 1) Un presupuesto muy bajo para los recursos de comunicación gubernamental, carente además de una estructura de reparto interministerial clara y racionalizada, 2) Carencia de coordinación de mensajes entre los diversos departamentos gubernamentales. Lanzamiento individualizado de campañas publicitarias, ruedas de prensa que se solapaban entre sí y contradicciones flagrantes en las declaraciones ante los medios, 3) Incluso en los casos en que estaba previsto algún tipo de comité coordinador entre secretarías de prensa, éste no se reunía. Se producían comparecencias del Director General de la Oficina del Presidente en las que se abordaban temas de departamentos y ministerios sin consultar 0 involucrar previamente a los responsables de comunicación de los mismos, 4) Rara vez, los responsables políticos solicitaban a sus técnicos de comunicación informes previos a la actuación política, 5) Gran desequilibrio entre el relativo buen funcionamiento de la Oficina de Comunicación del Presidente y el sistema de comunicación del Gabinete de Gobierno, 6) En lugar de un gobierno unido en torno a mensajes coherentes y estratégicamente coordinados, abundaban las improvisaciones y la falta de sistematización y 7) Falta de atención a la necesidad de investigación sobre la respuesta del público y los medios a las iniciativas informativas realizadas, estados de opinión sobre los asuntos problemáticos, etc.

Probablemente el mismo catálogo de deficiencias tendría que ser asumido por muchos países que se consideran desarrollados (España entre ellos), pero que no lo serán en términos de comunicación gubernamental sin una profunda reforma de las estructuras y mentalidad de sus responsables.

Que la tarea sea ardua no significa que no pueda intentarse, aun sabiendo que toda transformación será gradual e incompleta. Por consiguiente, cuantos más elementos hayan sido previstos, en mejores condiciones se estará de no ignorar objetivos cruciales de futuro, aun cuando resulte bien modesta la realidad presente. Con esa perspectiva requiere una mención especial el horizonte de una administración cibernética o comunicación "on-line" entre las instituciones del Estado y la Administración y los ciudadanos de a pie. Sin ocasión ahora de mayor detalle en este aspecto del "E-Gobierno" o "Gobierno Electrónico", conviene llamar la atención sobre la necesaria implantación de una red de portales y páginas web de la Administración, el Gobierno y la Presidencia. Ello constituirá uno de los mejores escaparates y formas racionales de ofrecer a los ciudadanos la vía de contacto y de acceso informativo eficiente y cotidiano que la filosofía de los servicios informativos directos del Estado democrático defiende.

En países donde el porcentaje de población con acceso a Internet y apetencia del mismo sea muy minoritario, la tentación de los responsables de la comunicación gubernamental puede ser la

\footnotetext{
17 "Communications 2000: a vision for government communication in South Africa (Comtask)". Informe remitido por la Comisión presidida por el Diputado Thabo Mbeki, en octubre de 1996, como resultado del proceso de investigación y debate desarrollado para adaptar a la nueva realidad de Sudáfrica, el sistema de comunicación gubernamental. Las conclusiones de este informe sirvieron de base para la puesta en marcha en 1998 del nuevo GICS del Estado sudafricano (cfr. Mbeki, 1996)
} 
de desentenderse de este capítulo. Pero aparte de ignorar con ello que el pequeño sector tecnológicamente avanzado será también el más activo en política y el más sensible a las mejoras comunicacionales del gobierno, sería perder de vista que en una era de globalización ninguna sociedad que aspire a mejorar su comercio -y todo lo que eso implica-, puede quedarse "desconectada" de las tendencias más dinámicas del resto. Y en mundo más avanzado resulta ya evidente que "la Red Cibernética Mundial (www) se ha convertido en un instrumento importante del gobierno para eliminar su imagen burocratizada y facilitar un servicio público más rápido" (Margasak, 1997), que también resultará en muchos casos más barato y de importante repercusión en el desarrollo. Pero como también la experiencia de naciones más evolucionadas viene reflejando, no se trata de que las oficinas de la Administración o el propio gabinete de gobierno estén presentes sin más en Internet, sino de aplicar las nuevas tecnologías a la facilitación real del contacto con los ciudadanos interesados y que éstos puedan obtener por sí mismos la información que requieran para sentir que el Estado actúa realmente a su servicio ${ }^{18}$ (cfr. entre otros, Margasak, 1997; Von Weyhe, 1999; Graber y White, 2001; Yeabsley y Bailey, 2001). La buena imagen de un gobierno y de un Presidente tiene por tanto también mucho que ver con ese escaparate virtual de páginas web eficaces y transparentes ${ }^{19}$ y no se reduce sólo a los más clásicos asuntos de la retórica política, las entrevistas en televisión o los contactos personales con el pueblo.

\section{LAS CLAVES DEL DISEÑO ESTRATÉGICO Y TÁCTICO DE LA IMAGEN PÚBLICA}

La red general de comunicación gubernamental y administrativa puede y debe alimentar una circulación diaria de mensajes útiles que constituyen el tejido básico de la representación de un Estado. Pero en la cúspide ejecutiva, la dirección de su gobierno requiere mostrar el vestuario brillante y adecuado que simbolice con claridad la voluntad y justificación de sus políticas. Ello exige una visión estratégica de lo que un gobierno quiere transmitir y debatir con carácter prioritario con sus ciudadanos. Sabido es que en el momento en que el Poder político se plantea qué mensajes o ideas han de ser propagados de forma pública, puede caer con facilidad -o resultar sospechosoen instaurar un inicuo aparato de propaganda. Es indudable que los abusos apuntados del maquillaje comunicativo en la era de la imagen pueden convertir las actuaciones de comunicación gubernamental en deleznables falsificaciones de la deliberación democrática. Pero no es menos cierto, que en la competencia de puntos de vista que todos los grupos de opinión esgrimen en una sociedad plural, el gobierno legítimamente establecido también tiene derecho -y hasta obligaciónde explicar sus decisiones y sus planes con la mayor eficacia argumentativa y solvencia de datos

\footnotetext{
${ }^{18}$ Como un simple ejemplo de página web gubernamental puede visitarse la del gobierno británico, centrada exclusivamente en aspectos de actualidad e imagen pública de su gabinete y concebida de forma autónoma al resto de páginas virtuales de la administración británica: www.number-10.gov.uk/

19 Para una buena reflexión sobre la integración entre instrumentos tradicionales y cibernéticos de información del Estado, así como una descripción actualiza del nivel de los diversos países de América Latina en la construcción de sus "gobiernos electrónicos", cfr. H. Vega, 2002:133-185
} 
que le sea posible. A la política democrática no le basta con ejecutarse, sino que requiere ser respaldada por la mayoría de los ciudadanos, y por eso mismo, tan importante como la realización de un programa de gobierno es que esas acciones puedan ser explicadas ${ }^{20}$.

Hacerlo con la suficiente claridad de pensamiento, sencillez y coherencia de exposición, y potencia de convencimiento, es sin duda el gran reto que asedia las mentes -y justifica la existencia-, de los asesores y directores de la política comunicacional de un gobierno. Asesorar y afrontar a diario el conflicto de explicar lo que el gobierno hace o quiere realizar resulta, sin duda, mucho más un arte de equilibrio entre el sentido común y la perspicacia psicosociológica, que la hipotética aplicación de algún manual de recetas infalibles.

Aun así, y teniendo en cuenta que cada sociedad es distinta y que las culturas políticas de cada comunidad obligan a una delicada adaptación, la experiencia acumulada y divulgada por algunos de los que más tiempo han dedicado a estas tareas en los países que más esfuerzo han invertido al respecto, puede orientar, como mínimo, los retos afrontados en otras latitudes. Entre los especialistas de este tipo que han publicado reflexiones sobre su experiencia (Gergen: 2000; Izurieta et al. 2002, entre otros), me limitaré aquí a sintetizar algunas de las recomendaciones expuestas en el libro conjunto del ya citado ex-asesor de Bill Clinton, Paul Begala y el experto en campañas electorales James Carville (Carville y Begala, 2002). Aunque tales recomendaciones han sido presentadas para la gestión de campañas electorales o de movilización y defensa empresarial, resultan en su mayoría también indispensables para la orientación de la "campaña permanente" que supone el sostenimiento en el Poder y su posible renovación por parte de un gobierno democráticamente elegido:

- No abandonar, nunca abandonar: La perseverancia, firmeza y tenacidad pueden ser factores más importantes, según estos expertos, que incluso los errores inicialmente cometidos. Ello no significa una obtusa terquedad en negar lo obvio, pues como indican en otros consejos, la flexibilidad y capacidad de autocrítica, pidiendo perdón incluso, son facetas tan decisivas como ésta. Pero con este criterio advierten contra el desaliento prematuro o la ofuscación inmediata ante situaciones de adversidad en las que el mandatario renunciara a defender convicciones 0 propuestas suficientemente valiosas. En la línea de que merece la pena resistir los ataques cuando las posiciones propias están bien cimentadas, recuerdan el dicho popular estadounidense de que "uno pierde el cien por cien de los tiros que no lanza" (lbid. 19 y ss.).

- Comprender la diferencia entre la estrategia y la táctica: Implícito en lo anterior aparece ya la diferencia entre los objetivos a largo plazo y las vicisitudes circunstanciales. Un error habitual entre muchos gobernantes y candidatos consiste en malgastar demasiada energía en pequeños

\footnotetext{
${ }^{20}$ Como indica Cook (1998:162), "los presidentes modernos no se ocupan de los medios simplemente por razones de ego, búsqueda de popularidad o agrado, se ocupan porque es parte de la tarea de un Presidente en los tiempos actuales"; otra cosa es, como denuncia Hannia Vega (2002:143), que el uso de los medios y otros servicios informativos por parte de los gobiernos se oriente tradicionalmente hacia intereses propagandísticos, en lugar de dar una respuesta más acorde con la necesidad de información transparente que demandan los periodistas, la oposición política y la sociedad civil.
} 
detalles tácticos que restan atención, o incluso provocan el desvío de los grandes objetivos que se perseguían a largo plazo ${ }^{21}$. Mantener en la mente el objetivo fundamental, con un diseño estratégico de múltiples pasos, y acometer ese plan con la flexibilidad táctica de primar más unos pasos u otros, según vayan surgiendo las circunstancias, es la aplicación de este principio que sugieren Carville y Begala (Ibid.: 82 y ss.). Idea que también expresan mediante una metáfora: "Un león es perfectamente capaz de cazar un ratón. Pero el esfuerzo de hacerlo no compensa el gasto energético. Un león no puede vivir a base de ratones, necesita antílopes" (Ibid.:89-90).

- Tener la iniciativa a la hora de fijar el marco del debate: La mayoría de los científicos de la comunicación política están convencidos de que en las democracias, el que define el debate gana el debate (o está mucho más cerca de lograrlo). Por ello la discusión entre partidos y medios de comunicación en las sociedades pluralistas se convierte cada vez más en un tira y afloja por el encuadre de lo que se debate -los aspectos que se resaltan de un tema y, por oposición, los que son condenados a pasar desapercibidos-. El entrenamiento de los gobernantes para establecer el encuadre que más les conviene de los asuntos y trastocar el planteado por los adversarios o los medios de comunicación, en entrevistas y comparecencias públicas, se convierte así en otra de las prioridades de la acción comunicativa gubernamental (ibid.: 68 y ss.).

Saber cómo comunicar (con el común denominador de la mayoría de la gente): Principio que se concreta en traducir a contar historias lo que se desea divulgar-dada la mayor atención de los seres humanos a la información que presenta estructura narrativa-, y que requiere también ser breves, ser emotivos, ser originales y conectar lo dicho con los puentes de implicación personal de los destinatarios - por las mismas razones de apelatividad narrativa que más fácilmente impactan al ser humano-. Los componentes de este saber comunicar desembocan a su vez, para los citados expertos en un "repetir sin descanso" los puntos o ideas centrales que se desea divulgar (lbid.: 108 y ss. $)^{22}$.

Saber cómo recuperarse cuando uno se ha venido abajo: Idea en la que a su vez se englobaría desde la flexibilidad para convertir la debilidad en fortaleza ${ }^{23}$, la flexibilidad para improvisar con acierto y para adaptarse a los cambios ambientales -sin perder tampoco el equilibrio en

\footnotetext{
${ }^{21}$ Sobre este particular dice también Izurieta (2002:244): "Pero no se puede comunicar todo. No se puede proyectar una imagen de todo. Hay que saber escoger qué proyectos o acciones (o la imagen de éstos) se promueven (o proyectan) (...) Luego se debe pensar y desarrollar el mejor "spin" (empaquetado o presentación) que le damos a ese elemento".

22 Sobre este mismo asunto, y recopilando las recomendaciones de otros cuantos expertos, añade lzurieta (2002:234): "Un mensaje efectivo debe ser: apropiado, recordable, entendible, creíble y tener sentido o significado (...) Pero sobre todo el mensaje debe ser simple (...) no se debe tratar de decir todo en un mensaje. El mensaje debe ser directo y contener sólo la idea central (...) La mente de las personas tiene tan sólo la capacidad de aceptar cierta cantidad de información al día (...) Entonces el mensaje debe ser repetitivo (...) El mensaje no son sólo palabras (...) el mensaje son también los símbolos, las expresiones y el tono de voz".

${ }^{10}$ A este respecto, los autores citan entre otros ejemplos cómo Jefferson, pésimo orador pero excelente escritor renunció a defender en la Asamblea su propuesta de Declaración de Independencia y consiguió que su silencio fuera más efectivo que la mejor elocuencia oratoria. Recuerdan también que Abraham Lincoln convirtió su aspecto tosco en una imagen de integridad y decencia (p. 150). Y apostillan: "Un buen vendedor sabe cómo convertir un pollo pasado de fecha en ensalada de pollo".
} 
cuestiones básicas de principios para no parecer un amoral o un pelele-, el cómo dar los pasos adecuados en una rectificación, pidiendo perdón si fuera necesario, y el afrontar la recuperación con espíritu de contraataque en el momento oportuno (lbid. 147 y ss. y 177 y ss.).

Estas cinco grandes orientaciones son en mi opinión las más destacables del valioso repertorio -mucho más amplio e ilustrado con situaciones reales- que Carville y Begala ofrecen. En él se explica también la necesidad de conjugar el saber alagar con el saber atacar a los grupos rivales (el viejo principio español de combinar sabiamente "el palo con la zanahoria"), la preponderancia de la franqueza y transparencia frente al secretismo, o la agilidad de reacción y anticipación ante los sucesivos problemas que puedan surgir en las campañas electorales o la acción de gobierno.

Pero del resto de sus atinadas observaciones me limitaré a citar finalmente la dinámica de trabajo que en la gestión de las campañas presidenciales de Bill Clinton hizo célebres a estos asesores. Me refiero a su "War Room", como la bautizó Hillary Clinton, refiriéndose a la estructura y mecánica de decisión diaria que establecieron en la cúspide de su equipo: Frente al común error de organizar complejas estructuras burocráticas con una gran distancia y cantidad de filtros entre los miembros de base y los últimos responsables de la maquinaria comunicativa, estos "comunicopólogos" idearon un núcleo jerárquico radial en el que todos los departamentos involucrados (investigación, publicidad, agenda de medios, etc.) tenían un representante. Dicho núcleo se reunía a diario a las 7.30 de la mañana en una entrevista que no podía durar más de 30 minutos. Ahí se establecía una prioridad de acción para todo el día y todo el equipo, y se concedían otros 30 minutos para que cada representante fuera a discutir con su propia sección cualquier alternativa u objeción que pudiera ocurrírseles. Tras pulir con estos detalles el plan definitivo toda la estructura comunicacional quedaba embarcada en un enfoque global, tanto a corto como a medio y largo plazo.

Este enfoque fue igualmente traspasado a la gestión de la comunicación presidencial, superando con ello muchas de las lentitudes de reacción, confusiones de iniciativa y pérdidas de información vital que se producen en organizaciones muy burocratizadas, donde cada propuesta ha de superar diversos filtros y en las que los mandos intermedios a menudo ignoran o se apropian de ideas de la base (por miopía, envidia o temor). Y para estimular a su vez la creatividad y espíritu innovador, se inculcó un ambiente de colaboración en el que "premiar más el riesgo de lo que se pudiera castigar el fallo". Pues en opinión de Carville y Begala, "una de las razones por las que las burocracias sienten tal aversión al riesgo es porque están orientadas a castigar mucho más el fallo que a premiar el éxito". Y añaden: "Si uno le da a una rata un trozo de galleta por hacer algo y luego dos descargas eléctricas por un error, lo más probable es que la rata se quede quieta sin hacer nada. El dolor de las descargas supera la ganancia de las galletas" (lbid. 60).

Una política de comunicación electoral fraguada bajo estos principios y dinámica se revela tan oportuna para los períodos de campaña como para el sostenimiento de una comunicación gubernamental y presidencial. Pero asimismo tiene que estar listas y engrasada estructuralmente, para afrontar las sorpresas que puedan surgir y cristalizar en situaciones de crisis, cuestión ésta que constituye el último aspecto del presente análisis: 


\section{EL ABORDAJE COMUNICATIVO DE LAS SITUACIONES DE CRISIS}

Todo responsable de una institución vislumbra la pesadilla del accidente material o simbólico que puede desatar una crisis y poner en riesgo las vidas y los bienes de la población, la estabilidad de la organización a su cargo o la continuidad de su propia función directiva. Los detonantes de una crisis - desde desastres naturales a actos de sabotaje o reacciones psicosociales comprensibles o ilógicas- escapan a menudo a la provocación directa de los dirigentes interpelados. Pero ello no evita que su responsabilidad en la aplicación de medidas y hallazgo de soluciones sea exigida con la máxima urgencia y prioridad frente a cualesquiera otras tareas. Además, con independencia de la sustancia material de las crisis más diversas, todas tienen en común que tanto el desarrollo de su percepción pública como el aspecto más sustantivo de su abordaje y resolución se articulan y deciden en una dimensión comunicativa.

Si hay un tipo de direcciones institucionales destinadas a sufrir crisis, esas son por definición los gobiernos y sus presidentes. Y dado que toda crisis es ante todo una crisis de comunicación y que su evolución seguirá en primer término la evolución que le marquen las reacciones comunicativas de los implicados, la estrategia de comunicación gubernamental y presidencial debe estar especialmente preparada para afrontar y solventar esos momentos convulsos y angustiosos en que unos acontecimientos de alarma social reclaman soluciones urgentes y eficientes en medio de la confusión y descontrol reinantes.

La reciente vida pública española aporta casos de estudio paradigmáticos para el análisis de las consecuencias y problemas de la comunicación gubernamental y presidencial en momentos de crisis. Y lo hace para las dos modalidades básicas que en mi opinión debieran distinguirse respecto a estas situaciones: las crisis anticipables o razonablemente previsibles y las inconcebibles (a primera vista) o salvajes ${ }^{24}$.

Las primeras serían aquéllas en las que las medidas y políticas públicas emprendidas o desarrolladas por un gobierno contienen el resorte de una fuerte controversia, hasta el punto de desatar reacciones intensas y extensas que concluyan en grave conflicto. A este género pertenece el clamor orquestado, con manifestaciones y huelgas incluidas, durante los meses finales de 2001 , en respuesta a la promulgación por el gobierno del Partido Popular de una nueva Ley de Universidades ${ }^{25}$. Hubiera debido preverse que un asunto tan controvertido y crónicamente deteriorado como ése en la sociedad española, y que al mismo tiempo afecta a tantos millones de población -en los diversos estamentos afectados-, podía disparar las reacciones más virulentas en el preciso momento en que se destapara la "lata de gusanos" que se venía incubando desde hacía varias décadas.

\footnotetext{
${ }^{24}$ Desde otro punto de vista se puede diferenciar también entre las crisis de base material (como un desastre natural, accidente industrial, etc.) y las de naturaleza simbólica o ético-política como un escándalo administrativo o personal, una polémica social, un cambio legislativo, etc.

${ }^{25}$ En esta modalidad cabría incluir también la crisis desatada por la decisión de Aznar de respaldar la guerra contra Irak. Pero el análisis de esta crisis, con implicaciones más complejas, requeriría un tratamiento mucho más minucioso del que permiten estas páginas.
} 
Los errores cometidos por el gobierno del PP en esta crisis -con movilizaciones de protesta generalizada en todas las universidades, campaña de fuerte descrédito en los medios de comunicación adversarios del gobierno, reactivación intensa de una oposición política y social hasta entonces muy adormecida y primeros indicios resultantes de pérdida sensible de respaldo electoral-, fueron mayúsculos por haber sido ante todo errores de comunicación y por tratarse de un horizonte de crisis que podía y debía haberse previsto, con un plan anticipado de respuestas ágiles e inmediatas para neutralizarla.

La dificultad de acometer una reforma de la universidad en España, que tantos intereses espurios soliviantaría con sólo intentarse, fue acometida con las únicas armas estratégicas del sigilo y la rapidez parlamentaria: Tras un largo período de vagas consultas a grupos de interés implicados, el proyecto de ley definitivo fue presentado y tramitado con carácter de urgencia en los meses de verano de 2001, divulgándose al comienzo de la reactivación académica, social y mediática, en septiembre, como un hecho consumado. El error "de libro" en esta maniobra consistió en no pensar en ningún momento bajo las perspectivas de reacción de los adversarios de la reforma -y de las fuerzas dispuestas a beneficiarse populistamente de la controversia-. La contundencia demagógica de las protestas de respuesta encontró así desprevenido al gobierno y le condenaron, a partir de ese momento a seguir toda la crisis desatada de manera reactiva, sin capacidad para ir marcando él la iniciativa ante la opinión pública ${ }^{26}$.

El segundo gran error, muy vinculado a la misma estrategia simplista, consistió en abordar la comunicación política de la reforma, en el momento inicial, desde el Ministerio de Educación exclusivamente, sin elevarla en el tratamiento y en la coordinación ministerial a comunicación política de todo el gobierno con su Presidente a la cabeza. Sin duda, la razón de este enfoque venía determinada por la pretensión de que -en una poco meditada aplicación de la teoría de la "agenda-setting "127 - el tema fuera escasamente percibido como crucial y pudiera ser "aislado" en un tono menor de tratamiento técnico, mientras la alta política del presidente y su gobierno discurría por territorios simbólicos más destacados y solemnes (preparación de la presidencia europea, etc.). Bien al contrario, los enemigos de la reforma universitaria captaron la atención popular sobre el asunto enarbolando tópicos tan clásicos como "la destrucción de la universidad pública en beneficio de las élites privadas", o "el autoritarismo de la derecha contra la independencia intelectual de las universidades críticas". La imagen proyectada fue entonces la de un ministerio de educación aislado y sin respaldo global, con una actuación supuestamente siniestra

\footnotetext{
${ }^{26}$ Como escribe Mordacai Lee (1999:445-446), una vez que un gobierno presenta una propuesta de tal o cual manera, es muy difícil cambiar esa primera percepción. O como remachan Carville y Begala (2002:54) "jintenta meter de nuevo la pasta de dientes en el tubo!". Esta expresión resulta especialmente gráfica para caracterizar lo sucedido en la crisis del petrolero "Prestige", descrita a continuación.

${ }^{27}$ En la vertiente complementaria de su formulación más clásica, esta teoría (cfr. McCombs y Shaw, 1972; Dader, 1990, entre muchos otros trabajos) viene a señalar que la gente no discute ni se opone a aquello de lo que no se habla o pasa desapercibido. Por consiguiente, el temor a que una información intensa sobre la reforma generara polémicas, llevó seguramente a preferir "un perfil bajo" a la hora de introducir el tema en la agenda pública.
} 
por ocultista, una ley confusa y plagada de errores y unas reacciones comunicativas gubernamentales que venían a reforzar la sensación de incomprensibilidad de la nueva ley y de retardada y débil respuesta ante las críticas. La "desinformación" puesta en circulación contra la nueva ley llevó a muchos universitarios y periodistas a creer que la ley aprobaba en algunos puntos justo lo contrario de lo que realmente respaldaba y resultó muy fácil de comprobar por cualquier que conviviera con universitarios que una exigua minoría había leído el texto o conocía con una elemental fidelidad las líneas básicas de su contenido. A pesar de lo cual, las consignas de huelga fueron secundadas por la práctica totalidad de los estudiantes, junto con importantes manifestaciones callejeras.

El gobierno del PP desperdició en este punto una clara ocasión de presentar en términos sencillos una reforma técnica decisiva como acción democrática de modernización en contra de los privilegios de mezquinas y endogámicas élites universitarias. Tendría que haber previsto que tan importante como el diseño legislativo habría de ser una planificación de su explicación mediática y ciudadana, divulgando, en los primeros momentos y de forma masiva, síntesis claras y exactas del contenido de su reforma, con referencias igual de sencillas de sus implicaciones socialmente positivas. De la ocasión para una gran campaña sobre la modernización y garantía de la calidad de enseñanza, se pasó en cambio a la imagen de un gobierno sospechoso de autoritarismo, de favorecer los negocios de la enseñanza privada y de perpetrar una chapuza técnica que empeoraría la situación previa.

El otro tipo de crisis sobrevenida, antes aludido, que sacude de forma sorpresiva y radical, y obliga a cambiar toda la agenda pública de las principales instituciones, queda nítidamente visualizado en el hundimiento del petrolero "Prestige" frente a las costas gallegas, en noviembre de 2002, provocando una "marea negra" sobre miles de kilómetros de litoral que llegó a alcanzar incluso a zonas de Francia y que ha seguido mostrando sus secuelas, casi un año después de producido el accidente.

Los errores en la gestión gubernamental y presidencial de esta crisis cabría calificarlos de espectaculares, produciendo un vertiginoso descenso del respaldo global al gobierno del PP, agravado de inmediato por la crisis de la guerra contra Irak. Por otro lado, las implicaciones estructurales y de organización de recursos materiales de este caso han resultado tan decisivas y se han revelado tan pésimamente preparadas para situaciones como la desencadenada, que el apartado de la gestión comunicacional de la crisis difícilmente podrá ser juzgado con ecuanimidad. Porque a la vista del tragicómico aluvión de sucesos negativos observados, cabría preguntarse si la actuación comunicativa del gobierno y su presidente fue un absoluto desastre que tiraba por los suelos su imagen de eficacia, o muy al contrario, constituyó un alarde de genialidad y buen hacer para que, en una situación material tan lamentable y pésimamente gestionada en sus dimensiones administrativas y materiales, el tratamiento comunicativo haya conseguido suavizar en gran medida los efectos simbólicos de la catástrofe.

La torpeza de una administración regional y estatal, incapaces de reaccionar en sincronía y mediante un plan racional preestablecido, demostró aquí que el trabajo de anticipación de crisis 
es determinante para el margen de éxito esperable en las reacciones forzadas tras el desastre natural o provocado por la acción humana. De forma esquemática los errores previos al tratamiento comunicacional de la crisis fueron, en mi opinión, los siguientes: ${ }^{28}$

- Ausencia de un plan de emergencias tipificado y sometido a un protocolo riguroso que además de estar formalizado, fuera de hecho utilizado en el momento del suceso ${ }^{29}$ (error estructural).

- Decisión de alejamiento del barco (a la postre muy dañina) adoptada por autoridades de rango medio, sin consultar a verdaderos especialistas y sin conocimiento previo de autoridades políticas de mayor responsabilidad (error coyuntural derivado del estructural anterior).

- Ausencia de control y de intervención política firme respecto al cambio de rumbo realizado por el barco averiado, quedando la cuestión a merced de la iniciativa privada y los intereses empresariales involucrados, en los momentos críticos de la catástrofe (error coyuntural por derivación del error estructural) ${ }^{30}$.

- Falta de agilidad en el despliegue organizacional de equipos de respuesta, una vez iniciada la marea negra. Hecho especialmente grave en la muy tardía llamada al ejército, aunque quizá por razones de tradición y mentalidad popular anti-militarista (combinación estructural y coyuntural).

Por lo que se refiere a la faceta comunicativa, si bien ésta venía muy condicionada por los citados fallos previos, que hicieron muy difícil paliar al menos la repercusión simbólica de la catástrofe, cabe también identificar los siguientes problemas estrictamente comunicacionales:

- Los servicios de comunicación gubernamental del Estado español no parece que dispongan de un reconocimiento efectivo para imponer en la práctica una coordinación y unificación de todas las dependencias comunicativas de los diferentes ministerios (repitiendo el problema ya advertido en otras crisis anteriores no aludidas hasta aquí, -caso de las "vacas locas" en 2001-. Los primeros días de la catástrofe era habitual escuchar diferentes y contradictorias "voces" ministeriales y/o territoriales) (error estructural).

\footnotetext{
${ }^{28}$ Para la reflexión que sigue se ha tenido en cuenta una gran cantidad de boletines audiovisuales y textos periodísticos difundidos entre noviembre de 2002 y febrero de 2003, entre los que han sido especialmente considerados los siguientes: Luis Gómez y Pablo Ordaz, "La marea negra alcanza La Moncloa" (El País, 4-12-02); Antonio Elorza, "El desprestigio" (El País, 6-12-02); Casimiro García-Abadillo, "Lecciones del 'Prestige'" (El Mundo, 9-12-02); Federico Jiménez Lozanitos, "El primero, soberbia" (El Mundo, 9-02-12), Casimiro García-Abadillo, "Daños políticos colaterales" (EI Mundo, 16-12-02) y Jorge De Esteban, "Los siete errores capitales" (El Mundo, 19-12-02).

${ }^{29}$ Según noticias de prensa, meses antes del accidente del "Prestige", las autoridades marítimas y de protección civil de La Coruña habían desarrollado un simulacro de accidente muy similar al luego producido, generando un extenso documento de recomendaciones a seguir. Dicho documento fue ignorado y jamás consultado durante los sucesos reales, según han denunciado diversos técnicos.

${ }^{30}$ Alguna información periodística más reciente ha señalado que en realidad el cambio de rumbo en la dirección más dañina para las costas españolas y portuguesas, fue en realidad decidida por el Gobierno español, ante las presiones de Francia por evitar que el rumbo contrario afectara más a sus costas.
} 
- Evidencia de una concepción de los gabinetes de comunicación gubernamental y presidencial como herramientas consultivas y subalternas, pero (a diferencia de los enfoques estadounidense y británico comentados) sin capacidad para imponer o compartir decisiones con el mismo rango de implicación que los equipos políticos. Ello limita la capacidad de las estructuras comunicativas de máximo nivel para orientar y organizar con carácter anticipatorio los criterios globales a seguir en la gestión integrada -material y comunicacional- de la crisis (error estructural).

- Ausencia previa de la figura institucionaliza de un "Jefe de Prensa del Gobierno" que hubiera servido de "cortafuegos" ante el Ministro Portavoz (Mariano Rajoy), quien por consiguiente tuvo que asumir la dura y constante tarea de ser la voz oficial indispensable durante toda la cri$\mathrm{sis}^{31}$.

- Carencia de un tratamiento visual de los aspectos positivos de la intervención reparadora de la Administración. El detalle más llamativo a este respecto es que a lo largo de dos meses no hubo una sola imagen en los boletines de televisión del trabajo de los grandes buques de limpieza realmente presentes en altamar y en la zona del hundimiento. Frente a las inevitables imágenes de la población sacando la pasta contaminante con las manos y con medios artesanales en la costa, hubiera resultado estimulante ver a los barcos especializados contratados por el Gobierno liberar de antemano a las cosas de una parte importante de los residuos. En su lugar, la imagen repetida hasta la saciedad del hilo de combustible pastoso ascendiendo desde el fondo submarino remachó durante semanas que el Gobierno era incapaz de frenar la continua afluencia de contaminantes.

- En la misma línea anterior se tardó semanas en presentar imágenes del ejército trabajando en la limpieza, frente a las continúas imágenes de vecinos y voluntarios trabajando desesperada y a menudo desorganizadamente. El error comunicacional en este punto venía motivado por el error material previo de las autoridades de no involucrar al ejército -salvo en una presencia testimonial-, hasta que los grupos de oposición comenzaron a denunciar duramente esta ausencia.

- Falta de una rápida y clara explicación de cómo la integración de los voluntarios en las tareas de limpieza se procuró coordinar con relativa rapidez por las autoridades asumiendo incluso la retribución por la Administración de estas actividades. El desconocimiento popular de este detalle alentó que mucha gente en el resto de España considerara bochornoso que la población perjudicada tuviera que actuar supuestamente sin remuneración y al mismo tiempo, en los pueblos afectados, muchos vecinos protestaban por la llegada de empleados de una empresa pública de limpieza que aparentemente les privaba a los lugareños de la posibilidad de cobrar unos salarios por el trabajo de limpieza, como complemento a las ayudas directas percibidas por la cesación de sus actividades laborales habituales.

\footnotetext{
${ }^{31}$ Sólo dos meses más tarde, en la fase ya suavizada de desenlace, el gobierno nombró un nuevo cargo público, con rango de Secretario de Estado, para asumir la coordinación del seguimiento. Dicho cargo es también de entidad política (Rodolfo Martín Villa) sin presentar un portavoz comunicacional específico.
} 
- Finalmente, frente a las duras críticas expresadas por los partidos políticos de oposición, la respuesta comunicativa del Gobierno no fue capaz de concretar y visualizar mucho mejor (hasta la fase más avanzada de la crisis) los errores cometidos por la oposición política. Ésta fue sólo acusada de una genérica "deslealtad" y "demagogia", pero sin una eficaz concreción ante la opinión pública de sus evidencias. Por ejemplo, cuando los líderes del partido socialista arremetían contra el error de sacar el barco a altamar en lugar de haberlo desviado a un puerto de refugio, el gobierno podía haber emplazado al líder de la oposición a que dijera en qué puerto hubiera él decidido llevar el barco averiado, para que esa zona aislada hubiera sido la única víctima del desastre. Como por razones populistas esa declaración hubiera sido muy improbable, su crítica a los errores iniciales habría quedado muy desactivada.

En esta larga y gravísima crisis no todo fueron errores por parte de la gestión material y comunicacional del gobierno, si bien las limitaciones de espacio impiden entrar en las rectificaciones y recuperación moderada de iniciativa que tras el desconcierto y lentitud iniciales fueron paliando la situación. Tampoco hay espacio ni fuentes suficientemente contrastadas para calibrar la incidencia -en la fase final de la crisis-, de viejas prácticas de censura y chantaje a técnicos especialistas y a población afectada para que se mantenga en silencio la verdadera dimensión de las gravísimas secuelas que (según algunos informantes que denuncian presiones de todo tipo), van a seguir afectando por largo tiempo a la zona. Como rápido contrapunto debiera también recordarse el tratamiento antagónico que a esta misma crisis supo dar el gobierno francés -favorecido por las semanas de atenta observación de los problemas de su vecino-, cuando finalmente la contaminación llegó a las costas francesas ${ }^{32}$. Los aciertos y los errores de unos y otros ilustran en todo caso que, como los diversos expertos en comunicación gubernamental conocen, las intervenciones sobre la imagen pública en situaciones polémicas constituyen un vertiginoso y resbaladizo toma y daca, en el que cada actor político involucrado puede enfrentar a sus competidores con un abanico de alternativas de difícil elección a priori.

El "caso del Prestige", por ello, como cualquier otro que fuera analizado, no es susceptible de un dictamen categórico. Pero al tratamiento de cualquiera de estas crisis, como al desarrollo de las estrategias de las comunicaciones gubernamentales, en sentido amplio, cabe cuando menos aplicarles los principios de persistencia en el esfuerzo, dinamismo y agilidad en las reacciones, y flexibilidad y creatividad en la intervención de equipos bien integrados de expertos variados, que los estrategas de Clinton, los citados Carville y Begala subrayan de entre sus consejos. Ello deberá aplicarse teniendo a su vez presente, como estos mismos autores indican (2002:159) que cada ambiente social y contexto organizativo plantea sus exigencias específicas, por lo que partiendo de las capacidades existentes habrá que generar un estilo o estructuración propia, evitando una

\footnotetext{
32 Cfr. por ejemplo, "Francia acelera la lucha contra el vertido porque no quiere repetir los errores de España" (El Mundo, 4-1-03); Octavi Martí, "Chirac ordena a su primer ministro supervisar sobre el terreno la lucha contra el vertido" (El País, 4-1-03); Ibid. "El crudo del 'Prestige' mancha ya más de cien kilómetros de la costa atlántica francesa" (El País, 5-1-03) y Soledad Alcaide, "Avalancha de medios técnicos" (El País, 5-1-03)
} 
concepción rígida o visión de una única forma posible de organizarse y explicarse. En último término, como también señalan Carville y Begala (2002:173), "las batallas no siempre las ganan los más fuertes, sino los que demuestran mayor versatilidad para adaptarse".

\section{REFERENCIAS BIBLIOGRÁFICAS}

- Alger, D. (1996): The Media and Politics, Belmont: Wadsworth Pub. Co.

- BBC (2002): "UK Politics, Profile: Alastair Campbell". BBC News. UK Politics, Profile, 14 de junio. http://news.bbc.co.uk/1/hi/uk_politics/2044775.stm

- Blumenthal, S. (1980): The Permanent Campaign, Boston: Beacon Press.

- Canel, M.J. (1999): Comunicación política. Técnicas y estrategias para la sociedad de la información, Madrid: Tecnos.

- Carville, J.; Begala, P. (2002): Buck up, Suck up...and Come back When You Are Foul up. 12 Winnings Secrets from the War Room, New York: Simon and Schuster.

- Cook, T. (1998): Governing With the News, Chicago: University of Chicago Press.

- Dader, J.L. (1990): "La canalización o fijación de la 'agenda' por los medios", en Muñoz Alonso et al. (1990): Opinión Pública y Comunicación Política, Madrid: Eudema.

- Édes, B. (2000): "The role of government information officers", Journal of Government Information, vol 27:4, Julio-agosto, pp. 455-469.

- Elliot, A. (2001): "La influencia de los medios de comunicación en las elecciones: España e Inglaterra". Trabajo del módulo de "Comunicación Política" en el Master de Comunicación Periodística, Empresarial e Institucional. Dpto. Periodismo III. Facultad de Ciencias de la Información. Universidad Complutense de Madrid.

- EPXNews (2002) "Spin has damaged politics, admits Campbell", EpxNews, 9 de mayo. www.epolitix.com/bos/epxnews/00000000636C.htm

- Ewen, S. (1996): PR! A Social History of Spin, New York: Basic Books.

- Gergen, D. (2000): Eyewitness to Power: The Essence of Leadership, Nixon to Clinton, New York: Simons and Schuster.

- Graber, D., White, B. (2001): "Medios interpersonales y comunicación política. Comunicación política y redes electrónicas", Cuadernos de Información y Comunicación $(\mathrm{ClC}), \mathrm{n}^{\circ} 6$.

- Hart, R. P. (1984) Verbal Style and the Presidency: A Computer-Based Analisis, Orlando: Academic Press.

- Izurieta, R. (2002): "La comunicación política en la era del entretenimiento: Un estudio de la comunicación y las relaciones públicas para gobiernos", en Izurieta et al. Op. cit.

- Izurieta, R. et al. (2002): Estrategias de comunicación para gobiernos, Buenos Aires: La Crujía.

- Kalb, M. (1998): "Fashioning the White House. Paul Begala, Counselor to the President", Press/Politics, vol 3:3, pp. 6-13.

- Kernell, S. (1986): Going Public. New Strategies of Presidential Leadership, Washington: D.C. Congressional Q. Press. 
- Lee, M. (1999): "Reporters and Bureacrats", Public Relations Review, Winter.

- MacGuire, K. (1999): "Now he must spin for himself", New Stateman, 6 de septiembre. www.newstateman.co.uk

- Margasak, G. (1997): "Servicing Citizens With the Internet", The Washington Post, "The Federal Internet Guide". 21 de abril. www.washingtonpost.com/wp-srv/politics/govt/fedguide/stories/services.htm

- Mbeki, T. (1996): Communications 2000: A Vision for Government Communication in South Africa: Comtask Report www.gcis.gov.za/docs/govcomm/

- McCombs, M., Shaw, D. (1972) "The Agenda-Setting Function of Mass Media", Public Opinion Quarterly, vol. 36:2.

- Noguera, F. (2002): "La campaña permanente", en Izurieta et. al. Op. cit.

- Norris, P. et al. (1999): On Message: Communicating the Campaign, London: Sage.

- Paletz, D. (1999): The Media in American Politics. Contents and Consequences, New York: Longman.

- Perloff, R. (1998): "Presidential Rhetoric" y ""Presidential Rhetoric: Genres and Impact", en Ibidem, Political Communication. Politics, Press and Public in America.

- Perry, R.(ed. 1986): Elecciones por ordenador, Madrid: Fundesco.

- Primier, A. (1989): Effective Media Planning, Lexington: Lexington Books.

- Rawnsley, A. (2002): "Mr. Blair versus the Barons", The Observer, 6 de junio. www.observer.co.uk/Print/0,3858,4434654,00html

- Regan, D. (1988): For the Record, San Diego: CA. Harcourt Brace.

- Seymour-Ure, C. (1997): "Editorial Opinion in the National Press"; en Norris, P., Gavin, N. (eds.) Britain Votes 1997, Oxford: University Press.

- Thompson, J. (ed. 2001): El escándalo político. Poder y visibilidad en la era de los medios de comunicación, Barcelona: Paidós.

- Vega, H. (2002): "La comunicación de gobierno e Internet", en Izurieta et. al. Op. cit.

- Von Weyhe, B. (1999): Government Communication via the Internet. Strategic Issues at the Dawn of the 21 st Century. M.A. Thesis. Institut d'Etudes Politiques de Strasbourg. http://fsinfo.cs.uni-sb.de/ weyhe/mem/

- Wirthlin, R. (1995): Estrategia electoral: Persuadir por la razón, motivar por la emoción. La estrategia de la comunicación política, Madrid: Editorial Complutense.

- Yeabsley, J., Bailey, D. (2001): As Seen from Levin: Improving Government Communication with Citizens. A Report from the Region. Repot to State Services Commission. New Zeland Institute for Economic Research (NZLIER) and Lazar Associates. www.e-government.govt.nz/docs/levin/levin.pdf . 